\title{
Selective neuropathy and preserved vascular responses in the diabetic Charcot foot
}

\author{
M.J.Stevens, M.E. Edmonds, A. V.M. Foster and P. J. Watkins \\ Department of Diabetes, Kings College Hospital, London, UK
}

Summary. Charcot arthropathy is a disabling complication of diabetic neuropathy. It is however, unclear why it occurs in only a small number of neuropathic patients. We have studied 12 diabetic patients ( 10 insulin-dependent) with an acute Charcot arthropathy, and compared their neuropathy and vascular responsiveness with 12 diabetic patients (10 insulindependent) with recurrent neuropathic foot ulceration, 12 diabetic control subjects ( 9 insulin-dependent) and 10 normal non-diabetic subjects. The Charcot arthropathy patients demonstrated a preservation of warm perception, $6(5.5)^{\circ} \mathrm{C}$, but complete loss of peripheral cold perception, $10(0)^{\circ} \mathrm{C}$, $p<0.001$ (median (interquartile range)). This contrasted with the ulcerated neuropathy patients, who had equally severe impairment of both warm and cold sensory thresholds, $10(0.5)^{\circ} \mathrm{C}$ vs $10(1)^{\circ} \mathrm{C}$, respectively, the diabetic control subjects who were able to detect a $2(1.3)^{\circ} \mathrm{C}$ warm stimulus and $3(3.5)^{\circ} \mathrm{C}$ cold stimulus and the normal subjects, whose warm threshold was $2(1)^{\circ} \mathrm{C}$ and cold was $2(1)^{\circ} \mathrm{C}$. Light touch perception at the foot was preserved in the Charcot patients 4 (4) g vs $100(50) \mathrm{g}, p<0.0002$, in the ulcerated neuro- pathy patients. Vibration perception at the great toe and cardiovascular autonomic function tests (heart rate variability, Valsalva ratio and postural systolic blood pressure fall) were abnormal in both the Charcot patients and ulcerated neuropathy group, with no differences seen between the two groups. Peak skin blood flow at the great toe in response to local heating was preserved in the Charcot arthropathy patients, 63.36 (28.72) flow units when compared to the diabetic and normal subjects, 62.72 (47) flow units and 76.3 (33.92) flow units, respectively and much greater than in the ulcerated neuropathy patients 28.94 (37.39) flow units, $p<0.0002$. The diabetic patients developing Charcot arthropathy thus have a neuropathy and vascular responsiveness which distinguishes them from diabetic subjects developing neuropathic ulceration. This may be important in the pathogenesis of the Charcot foot.

Key words: Charcot arthropathy, selective neuropathy, blood flow.
Diabetic neuroarthropathy (Charcot arthropathy) is a rare, although under-diagnosed complication of the diabetic neuropathic limb which may result from trauma acting on an insensitive foot. The association between destructive joint changes and neuropathy was first made by Mitchell in 1831 [1], some 37 years before Charcot made his classic description of the neuropathic joint in association with tabes dorsalis [2]. Charcot suggested the importance of "trophic" nerve fibres in the maintenance of bony integrity, which on disruption, resulted in a neuropathic joint in only a few weeks. The link between bony absorption and the hyperaemia secondary to sympathetic nerve damage was made by Leriche in 1927 [3], and later the importance of loss of protective joint sensibility was stressed [4]. "Trophic" fibres might be the small nerve fibres, which are damaged early in diabetic neuropathy [5]. This may result in both a somatic neuropathy, with loss of pain and temperature perception, caused by damage to small unmyelinated $\mathrm{C}$ fibres, and the smaller myelinated A delta fibres, and in an autonomic neuropathy resulting for example, in sympathetic vascular denervation $[6,7]$. Sympathetic neuropathy results in excess arteriovenous shunting $[8,9]$, which may precipitate bony resorption. Disorganisation may result from minor trauma on weakened bone, which has lost protective sensation.

Only a small number of diabetic patients with neuropathy develop a Charcot joint. We have previously found that some diabetic patients developing a Charcot arthropathy had a different vascular responsiveness to a local heat stimulus, when compared to diabetic neuropathic patients with foot ulcers [10]. We now wished to test the hypothesis that patients who developed neuroarthropathy, may have a neuropathy which distinguishes them from patients developing neuropathic foot ulceration alone. This 
Table 1. Clinical details of patients

\begin{tabular}{|c|c|c|c|c|}
\hline Clinical details & $\begin{array}{l}\text { Normal subjects } \\
(n=10)\end{array}$ & $\begin{array}{l}\text { Diabetic control } \\
\text { subjects }(n=12)\end{array}$ & $\begin{array}{l}\text { Charcot arthropathy } \\
\text { patients }(n=12)\end{array}$ & $\begin{array}{l}\text { Ulcerated neuropathy } \\
\text { patients }(n=12)\end{array}$ \\
\hline Male:female & $5: 5$ & $6: 6$ & $5: 7$ & $7: 5$ \\
\hline Insulin-dependent: non-insulin-dependent & 1 & $9: 3$ & $10: 2$ & $10: 2$ \\
\hline Duration of diabetes (years) & 1 & $23.0(14)$ & $22.5(12.8)$ & $24.8(15)$ \\
\hline Retinopathy BG: Proliferative & I & Nil & $5: 5$ & $5: 7$ \\
\hline Nephropathy (albustix positive) & 1 & Nil & 4 & 8 \\
\hline
\end{tabular}

Results expressed as means (1 SD)

$\mathrm{BG}=$ background

neuropathy may help determine the vascular response to trauma and the subsequent bony destruction which may ensue.

We have studied 12 diabetic patients with an acute Charcot arthropathy (duration less than 3 months), and have compared their neuropathy to 12 ulcerated neuropathic diabetic patients, 12 diabetic control subjects and 10 normal subjects. The vascular responsiveness to a local heat stimulus (under the control of sympathetic adrenergic nerve fibres) was also compared, using a laser Doppler flowmeter.

\section{Subjects and methods}

\section{Subjects}

Four groups of patients were studied, 12 diabetic patients with an acute Charcot arthropathy, 12 diabetic patients with neuropathic foot ulceration, 12 diabetic control subjects and 10 normal subjects.

Group 1. ( $n=12$, seven female five male). Diabetic patients (10 insulin-dependent) with an acute Charcot arthropathy. The mean age was 49.2 (range $28-69$ years, one patient being over 60 ) and the mean (SD) duration of diabetes was 22.5 (12.8) years.

These patients were obtained from consecutive presentations to the diabetic foot clinic. Charcot arthropathy was diagnosed in diabetic patients who presented with a hot, red swollen foot without evidence of active penetrating sepsis. All patients exhibited bony destruction with the characteristic changes of bone fractures, sclerosis and disorganization visible on radiography. Serum uric acid was not elevated in any of the patients, and none had evidence of a systemic arthropathy involving other joints. Four patients had a history of trauma which precipitated the neuroarthropathy, in two it had occurred 6 months after digital amputation for local sepsis and in six patients no precipitating cause could be elicited. All patients complained of "a dull, deep ache" in the foot, which was one of the most distressing symptoms. All patients were examined within 3 months of the diagnosis being made. Clinical details are given in Table 1.

Group 2. ( $n=12$, five female seven male). Diabetic patients ( 10 insulin-dependent) with neuropathic foot ulceration. The mean age was 51.5 (range 36-69 years, one patient over 60) and duration of diabetes was $24.8(15.0)$ years.

These patients all attended the diabetic foot clinic. All had a history of recurrent neuropathic foot ulceration and nine were actively ulcerated at the time of assessment. Ulceration typically was found under the 1 st to 5 th metatarsal head.
Group 3. ( $n=12$, six female six male). Diabetic control patients (nine insulin-dependent). The mean age was 48.3 (range 32-69 years, two patients over 60 ) and the duration of diabetes was $23.0(14.0)$ years.

None of these patients had symptoms from neuropathy, or abnormal signs: ankle reflexes were bilaterally present in all subjects. Their absence of neuropathy was subsequently confirmed by cardiovascular autonomic function testing. These patients were all free from diabetic microvascular complications, specifically, none had evidence of retinopathy (including background), or albuminuria. None had a history of foot sepsis or ulceration.

Group 4. ( $n=10$, five female five male). Non diabetic control subjects. The mean age was 50.1 years (range $31-65$ years, one patient over 60).

All the patients included in the study were free from peripheral macrovessel disease: foot pulses were palpable and all had ankle:brachial pressure ratios $\geq 1$. No patients were taking vasoactive drugs at the time of the study, although antibiotic therapy was permitted.

\section{Methods}

Cardiovascular autonomic neuropathy. The mean heart rate variability on six maximal breaths, an assessment of parasympathetic integrity, was recorded on a continuous trace $[11,12]$. The heart rate response to the valsalva manoeuvre (expiration against $40 \mathrm{~mm} \mathrm{Hg}$ maintained for $15 \mathrm{~s}$ ), a measure of both sympathetic and parasympathetic function [13] was also performed twice, and the mean value calculated.

The change in systolic blood pressure on standing from the supine position was recorded on an automated Dinamap blood pressure recorder (model $1846 \mathrm{Sx}$, Criticon Inc, Tampa, Fl., USA) for 5 min after standing and the maximal fall noted.

Peripheral sensory thresholds (autonomic and somatic neuropathy). All patients had clinical examination of the ankle reflexes, together with assessment of thermal, light touch and vibration thresholds. Tickle sensation was assessed by lightly drawing a blunt probe across the plantar surface of the foot. Subjective awareness of pain in the foot was recorded, but cutaneous pain thresholds were not assessed due to the lack of a reproducible test. Both feet were assessed in the Charcot arthropathy patients. The ulcerated neuropathy patients and the control subjects arbitrarily only had the left foot assessed. Thermal sensory thresholds. Thermal thresholds to warm and cool stimuli were independently measured from the lateral border of the dorsum of the foot using a Medelec Triple T Thermal Threshold Tester (Medelec Limited, Surrey, UK). Thermal stimuli are delivered to the skin by means of a metal thermode which utilises the Peltier 
effect, whereby heating or cooling of the thermode is achieved by changing the direction of current at the plate. The forced choice method of testing was used as this has previously been found to be a reliable method of testing $[6,14]$. A reference temperature of $32^{\circ} \mathrm{C}$ was maintained at the probe as this approximated the mean foot temperature in all the patient groups. The probe was placed on the dorsum of the foot and calibrated so that the rate of temperature change was $1^{\circ} \mathrm{C}$ per s. The probe was attached to the foot so that the pressure applied with each thermal test was kept constant. In this way the ability to perceive a warm or cool stimulus of up to $10^{\circ} \mathrm{C}$ magnitude was assessed.

Light touch threshold. Light touch perception was assessed using nylon monofilaments which were graduated to test the ability to detect a pressure of $4 \mathrm{~g}, 8 \mathrm{~g}, 50 \mathrm{~g}$ and $100 \mathrm{~g}$. The filament was applied to a test site of the foot and pressure was applied to just achieve buckling of the filament. It had previously been determined that the desired pressure was being applied when bucking occurred. Each filament was applied vertically to ten test areas of the foot, sites at which ulceration is most frequently seen, (under the 1st, 3rd and 5th metatarsal heads and toes, medial and lateral plantar borders of the foot, the heel and the dorsum of the foot) [15]. The patient's ability to accurately locate the stimulus as well as the pressure threshold detected was recorded. Each filament was applied six times in each test site. The patient had to be able to detect the pressure stimulus at all sites to be judged to have intact light touch sensation for any given filament.

Vibration threshold. The vibration sensory threshold was recorded at the tip of the great toe using a biothesiometer (Biomedical Instruments, Newbury, Ohio, USA) [6]. The test was performed six times and the mean value was recorded.

Skin blood flow assessment. Measurements of skin blood flow were made in a temperature controlled room, where the temperature was maintained at $22 \pm 1^{\circ} \mathrm{C}$. The patients had all fasted for $2 \mathrm{~h}$ prior to the assessment, and were resting in the supine position for $30 \mathrm{~min}$ to allow equilibration to take place. The foot to be tested was positioned at heart level, and was covered with an insulating sock so that the temperature was maintained between 32 and $34^{\circ} \mathrm{C}$. Blood glucose was in the range 5 to $14 \mathrm{mmol} / \mathrm{l}$ at the start of the assessment period, and none of the patients became hypoglycaemic during the study.

Laser Doppler flowmetry. A T.S.I. Laserflo' laser Doppler (model BPM403, TSI Inc., St. Paul, Minn., USA) was used to measure skin blood flow [15].

Tissue diffusely scatters laser light with the majority of photons being scattered by stationary structures. However, some of this light will hit moving erythrocytes, and as a result will experience a frequency shift according to the Doppler principle. The backscattered light that impinges on the photodetector will generate a photocurrent that can be processed to give blood flow related signals [19]. The flow signal has been found to correlate well with standard methods of measuring skin blood flow [20-22].

The protocol for skin blood flow measurement. The heat stimulus was provided by a thermostatically controlled heater incorporated into the end of a standard right angle skin probe (TCM 420, TSI Inc). The range of the heating module was $35^{\circ} \mathrm{C}$ to $45^{\circ} \mathrm{C}$ in $0.1^{\circ} \mathrm{C}$ steps. This skin probe ( $2.5 \mathrm{~cm}$ diameter) was attached to the pulp of the great toe using an adhesive ring. Foot temperature was measured from the dorsum of the foot over the $3 \mathrm{rd}$ metatarsal using a digital thermometer (model H 400, Hale Instruments Ltd, Cheshire, UK).

The flow signal from the laser Doppler was recorded continuously during the measurement period on a microcomputer (BBC Master, Acorn Computers, London, UK) [10]. When a steady flow signal had been obtained, basal skin blood flow was recorded for $3 \mathrm{~min}$, from which a mean value for flow was calculated. The skin of the toe pulp was then heated locally to $44^{\circ} \mathrm{C}$ for $7 \mathrm{~min}$ as this period of time had previously been determined to be adequate to achieve peak flow [10]. The time of maximal increase (vasodilatation) or decrease (vasoconstriction) of skin blood flow over basal levels was recorded after the start of heating and a mean value was calculated over $10 \mathrm{~s}$ of steady flow at this point. This relatively short period of time was chosen as the peak flow signal starts to decrease quickly, and so a short averaging time is required to ensure that true peak flow is calculated.

Arbitrarily, skin blood flow from the left foot was chosen in all the patients without Charcot arthropathy, and if ulceration involved the base of the 1st digit, then the 2 nd digit was assessed. In the Char-

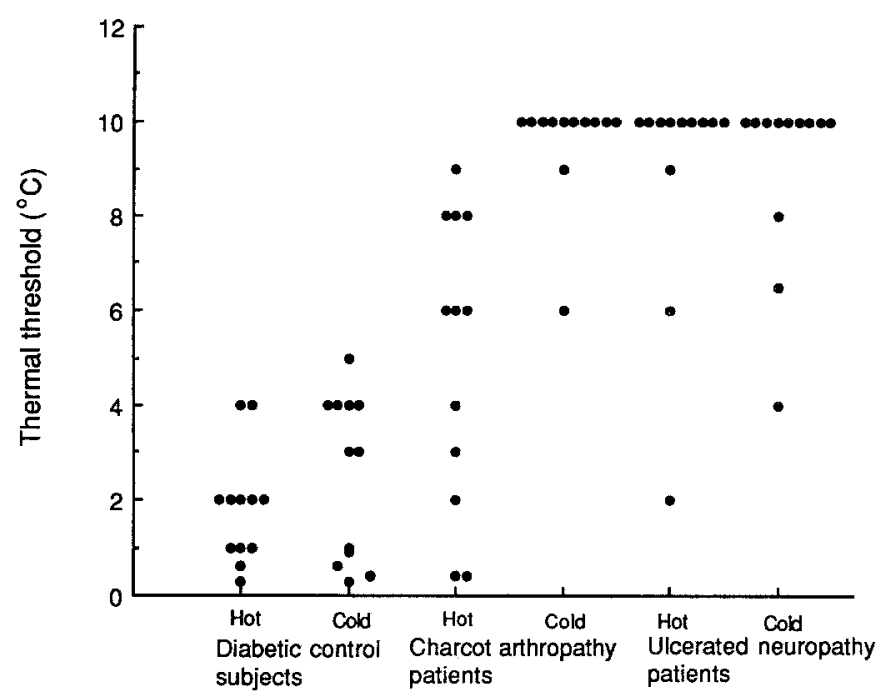

Fig. 1. Thermal thresholds to warm and cold stimuli measured separately on the dorsum of the foot from a reference temperature of $32^{\circ} \mathrm{C}$. Thresholds measured in the range $22^{\circ} \mathrm{C}$ to $42^{\circ} \mathrm{C} . p<0.001$, hot vs cold, Charcot arthropathy patients; $p<0.0005$, ulcer patients vs diabetic control subjects; $p<0.0002$ cold, Charcot patients vs diabetic control subjects; $p<0.05$ hot, Charcot patients vs diabetic control subjects

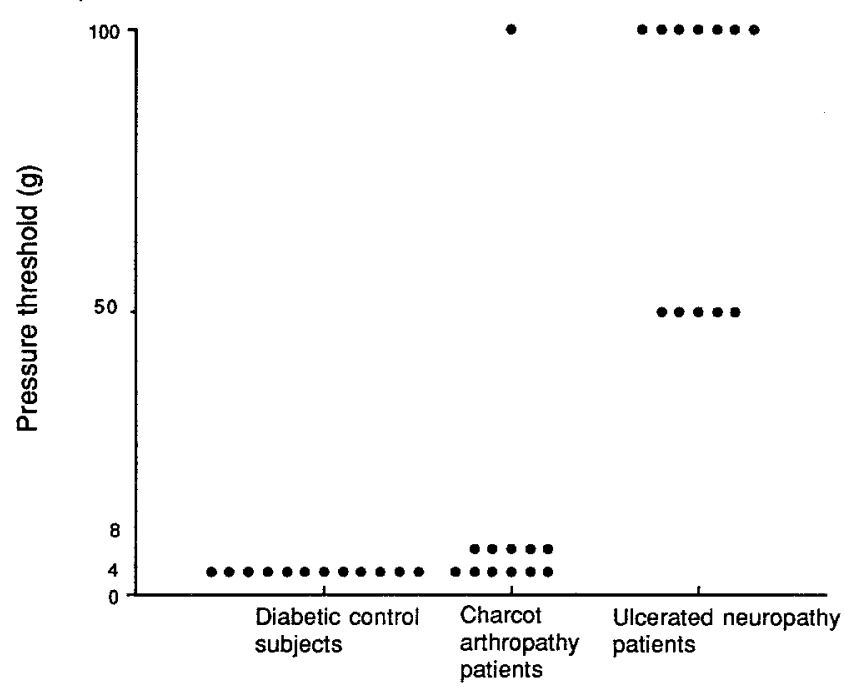

Fig. 2. Light touch perception, measured using graded nylon filaments (from $4 \mathrm{~g}$ to $100 \mathrm{~g}$ ) in diabetic control subjects, Charcot arthropathy patients and ulcerated neuropathy patients. $p<0.0001$, ulcer patients vs diabetic control subjects; $p<0.0002$, Charcot patients vs ulcer patients; $p<0.05$, Charcot patients vs diabetic control subjects 
Table 2. Cardiovascular autonomic function test

\begin{tabular}{|c|c|c|c|c|}
\hline Autonomic function tests & Normal subjects & $\begin{array}{l}\text { Diabetic control } \\
\text { subjects }\end{array}$ & $\begin{array}{l}\text { Charcot arthropathy } \\
\text { patients }\end{array}$ & $\begin{array}{l}\text { Ulcerated neuropathy } \\
\text { patients }\end{array}$ \\
\hline $\begin{array}{l}\text { Heart rate variability (beats } / \mathrm{min}) \\
\text { Normal }>12 \text { beats } / \mathrm{min}\end{array}$ & $\begin{array}{l}26(10) \\
\text { (range 17-39) }\end{array}$ & $\begin{array}{l}23.5(4.5) \\
\text { (range 13-31) }\end{array}$ & $\begin{array}{l}3.0(4) \\
\text { (range 1-11) }\end{array}$ & $\begin{array}{l}2.5(2.5) \\
\text { (range 1-5) }\end{array}$ \\
\hline Valsalva ratio (normal > 1.2) & $\begin{array}{l}1.5(0.2) \\
\text { (range } 1.3-1.7)\end{array}$ & $\begin{array}{l}1.40(0.1) \\
\text { (range 1.21-1.69) }\end{array}$ & $\begin{array}{l}1.11(0.2) \\
\text { (range 1-1.84) }\end{array}$ & $\begin{array}{l}1.14(0.2) \\
\text { (range 1.05-1.5) }\end{array}$ \\
\hline Postural systolic blood pressure fall & Nil & Nil & $30.5(15)$ & $20(15)$ \\
\hline
\end{tabular}

Results expressed as medians and interquartile range

cot patients, skin blood flow was recorded in both feet. This was to measure the acute variations in blood flow (both in the bone and skin) which occur during active bony destruction. The contralateral uninvolved limb acted as the control, allowing assessment of the influence of neuropathy on the vascular responsiveness in a patient with neuroarthropathy.

Reproducibility. The reproducibility of the peripheral neuropathy assessment was assessed by testing a patient with an acute neuroarthropathy on three separate occasions, separated in time by at least 1 week. The reproducibility of skin blood flow assessment was assessed by testing an ulcerated diabetic neuropathy patient and a diabetic neuroarthropathy on three separate occasions and the coefficient of variation of the peak flows was calculated.

The study was approved by the local ethical committee and informed consent was obtained from all the subjects studied.

\section{Statistical analysis}

As the data was not normally distributed, a Mann Whitney U Test was used to assess significance in non-paired observations, and a Wilcoxon's Signed Rank Test for paired data.

\section{Results}

The diabetic patients with Charcot's arthropathy, demonstrated a preserved ability to detect a warm stimulus 6.0 (5.5) ${ }^{\circ} \mathrm{C}$ within the $10^{\circ} \mathrm{C}$ range in the Charcot foot, but complete loss of peripheral cold perception, $10(0)^{\circ} \mathrm{C}(\mathrm{me}-$ dian (interquartile range)), $p<0.001$ (Fig.1). There was, however, some impairment of warm perception when Charcot patients were compared to the diabetic control subjects $2(1.3)^{\circ} \mathrm{C}$ and the normal subjects $2(1)^{\circ} \mathrm{C}$, $p<0.05$. The inability to feel cold, contrasted with the diabetic control subjects and normal subjects who were able to detect $3(3.5)^{\circ} \mathrm{C}$ and $2(1)^{\circ} \mathrm{C}$ cold stimulus, $p<0.0002$, respectively. The ulcerated diabetic neuropathy patients had equally severe impairment of both hot and cold thresholds, $10(0.5)^{\circ} \mathrm{C}$ vs $10(1)^{\circ} \mathrm{C}$, respectively, $p<0.0005$. Five of 12 Charcot patients had a warm threshold within the range of the diabetic control subjects $\left(0.5-4^{\circ} \mathrm{C}\right)$. Two Charcot patients were able to detect a warm stimulus of less than $0.5^{\circ} \mathrm{C}$, but were unable to feel a $10^{\circ} \mathrm{C}$ cold stimulus.

Light touch perception was also preserved in the Charcot foot 4 (4) g, when compared to the ulcerated neuropathy patients $100(50) \mathrm{g}, p<0.0002$ (Fig. 2). Six of the Charcot arthropathy patients had intact light touch (defined as the ability to detect the $4 \mathrm{~g}$ filament), and a fur- ther five were able to detect an 8 g pressure. Only one patient had severe impairment of light touch. Tickle perception was retained in 10 of 12 of the Charcot patients: four patients finding the stimulus particularly acute.

The ability to detect vibration was abnormal in both the Charcot arthropathy patients and the ulcerated neuropathy patients, when compared to the diabetic and non diabetic control groups, 29 (24) volts (V), 37.5 (24) V, 8 (5) $\mathrm{V}$ and $5.5(4.5) \mathrm{V}, p<0.0001$, respectively (Fig. 3). None of the Charcot arthropathy patients demonstrated preservation of vibration detection at the great toe.

Similar peripheral sensory thresholds were found bilaterally in the Charcot patients. There were no significant differences found between the diabetic control subjects and normal subjects in autonomic or peripheral neuropathy testing.

Cardiovascular autonomic function tests (heart rate variation and Valsalva ratio, and systolic blood pressure fall) were abnormal in both the Charcot arthropathy patients, and in the ulcerated neuropathy patients, when compared to the diabetic and normal control groups, $p<0.005$. The results are shown in Table 2. There were no differences found between the Charcot patients and the ulcerated patients.

Peak skin blood flow in response to local heating of the toe pulp was preserved in the Charcot arthropathy pa-

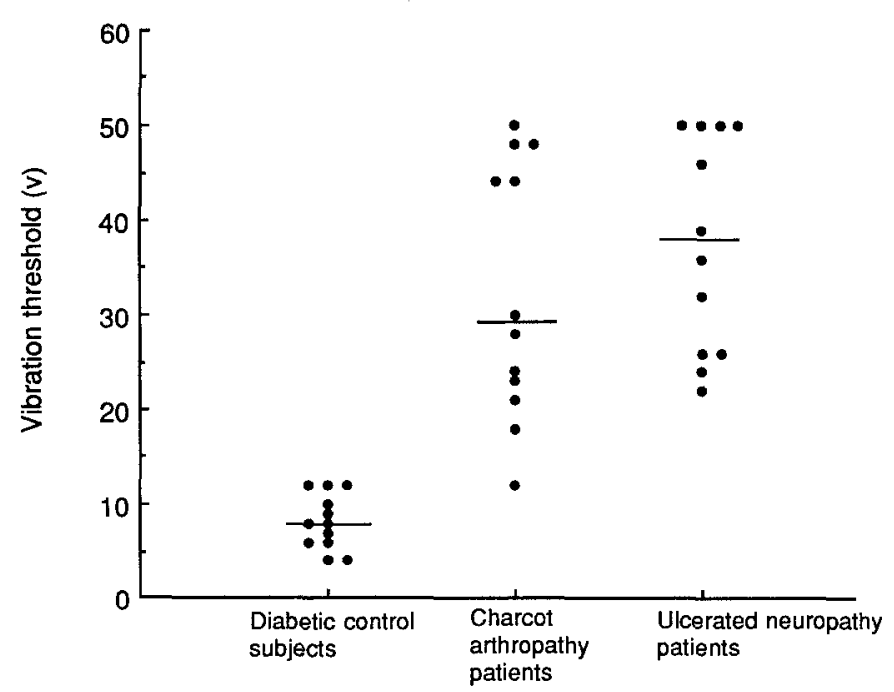

Fig.3. Vibration perception at the great toe measured with a Biothesiometer. Horizontal bars represent median values. $p<0.0001$, Diabetic control subjects vs Charcot arthropathy and ulcerated neuropathy patients 


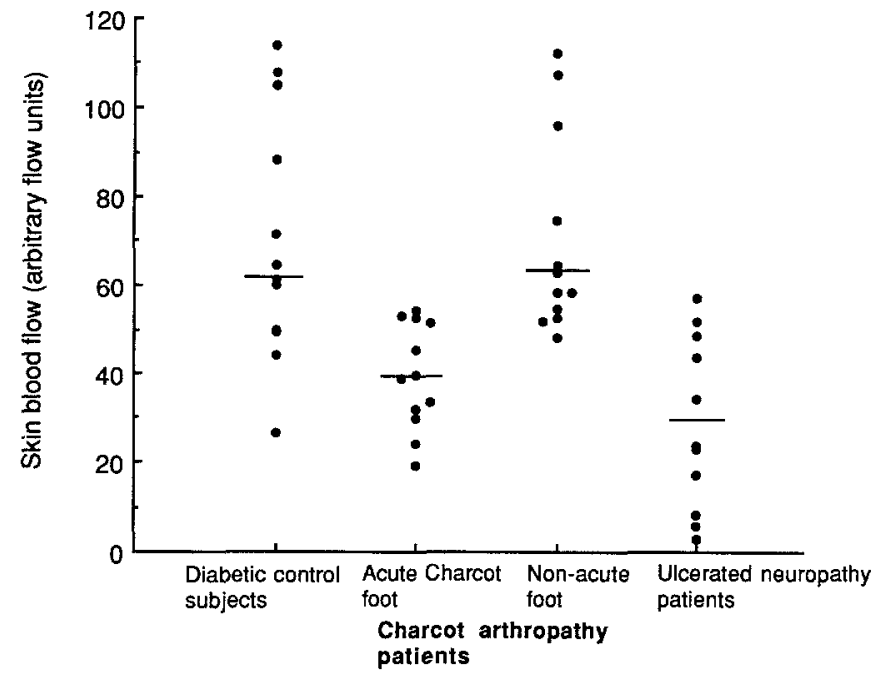

Fig.4. Peak skin blood flow on heating the toe pulp to $44^{\circ} \mathrm{C}$ for 7 min. Horizontal bars represent median values. $p<0.0002$, ulcerated neuropathy patients vs Charcot arthropathy patients (unaffected foot) and diabetic control subjects; $p<0.002$, acute Charcot foot vs non-acute contralateral foot

tients, 63.36 (28.72) flow units, when compared to both the diabetic control subjects 62.72 (47) flow units and normal subjects 76.3 (33.92) flow units, who had similar peak flow responses and much greater than in the ulcerated diabetic neuropathy patients 28.94 (37.39) flow units, $p<0.0002$. Peak flow was, however, transiently reduced in the acute Charcot foot compared to the contralateral uninvolved foot, 41.03 (19.16) vs 63.36 (28.76) flow units, respectively $p<0.002$ (Fig. 4). Six patients were reassessed after resolution of the acute inflammatory changes. All the patients demonstrated an increase in peak flow in the Charcot foot on resolution, flow increasing from 43.8 (12.88) to 64.1 (31.0) flow units, $p<0.02$ (Fig. 5).

Eight of 12 of the Charcot patients demonstrated vasoconstriction and a reduction of flow during local heating: skin blood flow in this group declined to $58.3 \%, p<0.05$ of its basal value. This vasoconstriction response was also seen in 9 of 12 ulcerated neuropathy patients, flow declining to $62.5 \%, p<0.05$ during heating. The vasoconstriction in the Charcot group was, however, followed by vasodilatation which resulted in preservation of the peak flow achieved.

Basal skin blood flow in the Charcot patients was higher than in the ulcerated neuropathy patients, the diabetic control subjects and normal subjects, 17.6 (15.7), 14.4 (17.44), 9 (10.9), and 11.96 (23.9) flow units, respectively, but the difference did not achieve statistical significance.

\section{Reproducibility}

The absence of cold perception was confirmed by repeat assessment on three separate occasions in one of the Charcot patients. The ability to perceive the warm stimulus had a coefficient of variation (SD/mean \%) of $5 \%$. The coefficient of variation for peak skin blood flow in the ulcerated

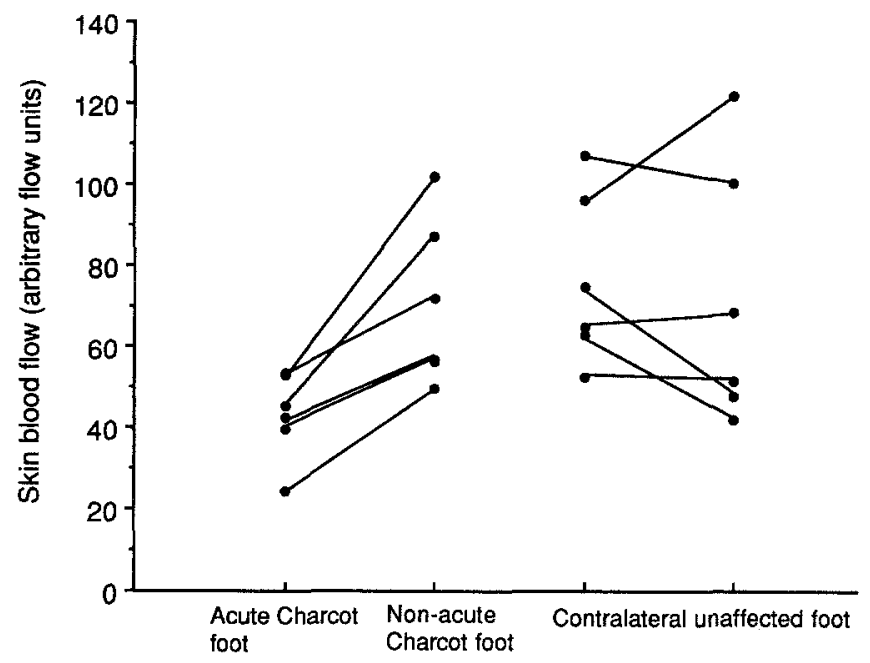

Fig.5. Change in peak skin blood flow of the Charcot foot on resoIution of the acute inflammation in six diabetic patients (range 4 to 9 months). The change in flow of the contralateral foot over the same time is shown for comparison. $p<0.02$ acute vs non-acute Charcot foot

neuropathy patient was $12 \%$ and $3 \%$ in a Charcot arthropathy patient.

\section{Discussion}

We have been able to show, that patients demonstrating Charcot's arthropathy have a peripheral neuropathy and vascular responsiveness which distinguishes them from diabetic patients developing recurrent neuropathic foot ulceration: the Charcot patients had preserved light touch and warm perception and peak skin blood flow achieved by local skin heating in the non-acute Charcot foot and the contralateral foot, was similar to diabetic control subjects. The selective preservation of warm fibres is the first demonstration in diabetic neuropathy of an unequal loss of peripheral small thermal fibres, which may indicate that some small nerve fibres are more susceptible to damage than others.

Sharp pain, like cold perception was reported by the Charcot patients to be lost in both feet, but they all reported dull continuous pain in the Charcot foot, with periodic exacerbations. The patients with ulceration reported little pain of any type: the foot was described as being numb. Small nerve fibres may be damaged early in diabetic neuropathy resulting in both somatic and autonomic nerve damage $[5,6]$. Cold and sharp pain perception is conveyed by small myelinated fibres (A delta fibres), warmth and deep pain by unmyelinated $C$ fibres [23-25]. The relative preservation of warm and deep pain suggests that these fibres seem more resistant to damage in Charcot patients. Warm thermoreceptors respond to temperatures within the range $32^{\circ} \mathrm{C}$ to $46^{\circ} \mathrm{C}$. Cold receptors are active below cutaneous temperatures of $30^{\circ} \mathrm{C}[26$, 27]. Our reference probe temperature at $32^{\circ} \mathrm{C}$ was at the thermoneutral value [28] and the range of test temperatures used $\left(22-42^{\circ} \mathrm{C}\right)$ provided equal stimulation of each 
type of receptor. Pain occurs when the intensity of a stimulus exceeds a certain threshold and results from the simultaneous stimulation of many neurons $[29,30]$. Substance $P$, which may be depleted in diabetic neuropathy [31] transmits impulses from primary afferent nerves conveying nociceptive and thermal information: depletion (which may not be equal in the Charcot and ulcerated neuropathy patients) may result in impaired nociceptor function. Selective damage to thermal and nociceptive nerve fibres, neurotransmitters or their receptors, may thus characterise Charcot arthropathy patients, occurring earlier than impaired vibration perception, which is conveyed by the larger $\mathrm{A} b$ fibres [6].

Only one of the Charcot patients did not have preserved light touch and tickle perception, and reported paraesthesiae and numbness. This patient had a history of recurrent foot ulceration. The ability to detect pressures of $8 \mathrm{~g}$ or less therefore seemed to protect from foot ulceration. Light touch receptors are thought to be the subcutaneous Meissner corpuscles and Merkel cell neurite complexes: at least in the human finger, there is extensive overlap of their receptive fields $[32,33]$. Light touch and vibration perception are large myelinated fibre function, although it is not clear whether they are conveyed separately. Although it is possible that the nerve fibres themselves are damaged at differing rates, the extensive overlap of the receptive fields subserving light touch may allow normal sensation to be maintained, even when some afferent units have been lost. The preservation of tickle perception (small unmyelinated $\mathrm{C}$ fibres) suggests that these sensory units are resistant to injury in the Charcot arthropathy patients.

The cardiovascular autonomic function tests, were abnormal in both the Charcot and the ulcerated neuropathy patients. Therefore, loss of cardiac autonomic innervation occurs equally in both groups of patients together with loss of peripheral vascular tone.

Peak skin blood flow at the toe (predominantly arteriovenous shunt flow) was preserved in the Charcot arthropathy patients, although acutely the Charcot foot behaved like the ulcerated neuropathic foot with decreased peak skin blood flow responses. This may have resulted from a transient loss of vascular control, which improved in the non-acute foot: in the ulcerated neuropatic foot the loss of vascular control seemed permanent. A reduction of peak skin blood flow may suggest that there is redistribution of flow away from the toes into bone [34]. There may exist sympathetic vasodilator fibres which precipitate vasodilatation in response to heating $[35,36]$. The selective neuropathy in the Charcot patients may spare these fibres permitting maximum vasodilatation to take place. There is, however, evidence of peripheral vascular denervation in both the Charcot patients and the ulcerated neuropathy patients, as paradoxical vasoconstriction and reduction of blood flow was seen during local heating which may reflect vascular denervation and result from abnormal local reflex vascular control [10]. The greatly reduced peak flow in the ulcerated diabetic patients resulted from persistent vasoconstriction of skin blood flow on heating and failure of subsequent vasodilatation. Increased vessel tone [37], microvascular sclerosis [38], and lack of local dilating vasoactive metabolites, for example endothelium derived relaxing factors and prostaglandins $[39,40]$ may contribute to the absent vasodilatation in these patients.

We have, therefore, shown that patients demonstrating Charcot arthropathy have a peripheral neuropathy and vascular responsiveness which clearly distinguishes them from ulcerated neuropathy patients. It is not clear whether our findings represent a distinct type of diabetic neuropathy, or is a stage in its development. The findings in particular, of preservation of light touch but loss of vibration perception is unusual in diabetic neuropathy and may be evidence of a unique form of neuropathy. Charcot in his original description referred to "trophic nerves" which are essential for bony integrity. Perhaps these are the small A delta fibres conveying pain and cold or the sympathetic fibres controlling arteriovenous shunt flow, which have been damaged in these patients. High bone shunt flow may precipitate bony resorption, which together with the ability to further greatly increase blood flow in response to trauma, and the loss of pain sensation, may result in the bony destruction and the formation of a neuropathic joint. Further studies on the evolution of the neuropathy are now required.

Acknowledgement. M.J.S. was supported by the British Diabetic Association.

\section{References}

1. Mitchell $\mathbf{J}$ (1831) On a new practice in acute and chronic rheumatism. Am J Med Sci 8: 55 64

2. Charcot JM (1868) Sur quelques arthropathies qui paraissant dependre d'u une lesion du cerveau ou de la maelle epiniere. Arch Physiol Norm Pathol 1: 161-178

3. Leriche R (1927) Sur quelques maladies osseuses et articulares d'origine vasomotrice et sur leur traitment. Bull Mem Soc Nat Chir 52: 1022-1030

4. Delano PJ (1946) The pathogenesis of Charcot's joint. Am J Radiol 56:189-200

5. Said G, Slama G, Selva J (1983) Progressive centripetal degeneration of axons in small fibre type diabetic polyneuropathy. Clin Pathol Study Brain 106: 791

6. Guy RJC, Clark CA, Malcolm PN, Watkins PJ (1985) Evaluation of thermal and vibration sensation in diabetic neuropathy. Diabetologia 28: 131-137

7. Watkins PJ, Edmonds ME (1983) Sympathetic nerve failure in diabetes. Diabetologia 25:73-77

8. Edmonds ME, Roberts VC, Watkins PJ (1982) Blood flow in the diabetic neuropathic foot. Diabetologia 22: 9-15

9. Cronenwett JL, Lindenaur SM (1977) Direct measurement of arteriovenous blood flow after lumbar sympathectomy. Surgery 82 : $82-89$

10. Stevens MJ, Edmonds ME, Douglas SLE, Watkins PJ (1991) The influence of neuropathy on the microvascular response to local heating in the human diabetic foot. Clin Sci 80:249-256

11. Wheeler T, Watkins PJ (1973) Cardiac denervation in diabetes. BrMed J 4: 584-586

12. Ewing DJ, Clarke BF (1982) Diagnosis and management of diabetic autonomic neuropathy. Br Med J 285: 916-918

13. Ewing DJ, Martyn CN, Young RJ, Clarke BF (1985) The value of cardiovascular autonomic function tests: 10 years experience in diabetes. Diab Care 8: 491-498

14. Fruhstorfer H, Lindblob U, Schmidt WG (1976) Method for quantitative estimation of thermal thresholds in patients. J Neurol Neurosurg Psychiatry 39: 1071-1075 
15. Birke JA, Sims DS (1986) Plantar sensory threshold in the ulcerative foot. Lepr Rev 57: 261-267

16. Rendell M, Bergman T, O'Donnell G, Drobny E, Bargos J, Bonner RF (1989) Microvascular blood flow, volume and velocity measured by laser Doppler techniques in IDDM. Diabetes 38 : 819-824

17. Anderson RR, Parrish JA (1981) The optics of the human skin. $J$ Invest Dermatol 77: 13-19

18. Kolari PJ (1985) Penetration of unfocused laser light into the skin. Arch Dermatol Res 277:342 -344

19. Shepherd AP, Oberg PA (1990) Laser Doppler blood flowmetry. Kluwer Academic Publishers, Norwell, MA

20. Tooke JE, Ostergren J, Fagrell B (1983) Synchronous assessment of human skin microcirculation by laser Doppler flowmetry and dynamic capillaroscopy. Int J Microcirc Clin Exp 2:277-284

21. Engelhart M, Kristensen JK (1983) Evaluation of cutaneous blood flow responses by 133 xenon washout and a laser Doppler flowmeter. J Invest Dermatol 80: 12-15

22. Saumet JL, Dittmar A, Leftheriotis G (1986) Non invasive measurement of skin blood flow: comparison between plethysmography, laser Doppler Flowmeter, and heat thermal clearance method. Int J Microcirc Clin Exp 5: 73-83

23. Le Quesne PM, Fowler CJ (1986) A study of pain threshold in diabetics with foot lesions. J Neurol Neurosurg Psychiatry 49: 1191-1194

24. Lindblom U (1980) Quantitative testing of sensibility including pain. In: Stalberg E, Young R (eds) Clinical Neurophysiology. Butterworths, London, pp 169-190

25. Thomas PK, Eliasson SG (1984) Diabetic neuropathy. In: Dyck PJ, Thomas PK, Lambert EH, Bunge R (eds) Peripheral neuropathy, 2nd edn. W. B. Saunders, Philadelphia, pp 1773-1810

26. Hensel $\mathrm{H}$, Iggo A (1971) Analysis of cutaneous warm and cold fibres in primates. Pflügers Arch Physiol 329: 1-8

27. Iggo A, Young DW (1975) Cutaneous thermoreceptors and thermal nociceptors. In: Kormbuber HH (ed) The somatosensory system. Thieme, Stuttgart

28. Gagge AP, Stevens JC (1968) Thermal sensitivity and comfort. In: Kenshalo DR (ed) The skin senses. C. C. Thomas, Springfield

29. Parkhouse N, Le Quesne PM (1988) Quantitative objective assessment of peripheral nociceptive $C$ fibre function. I Neurol Neurosurg Psychiat 51: 28-34
30. Torebjork HE, Hallin RG (1974) Identification of afferent C units in intact human skin nerves. Brain Res 67: 387-403

31. Levy DM, Karanth SS, Springall DR, Polak JM (1989) Depletion of cutaneous nerves and neuropeptides in diabetes mellitus: an immunocytochemical study. Diabetologia 32:427-433

32. Johansson RS (1978) Tactile sensibility in the human hand: receptive field characteristics of mechanoreceptive units in the glabrous skin area. J Physiol 281: 101-123

33. Johansson RS, Vallbo AB (1979) Tactile sensibilty in the human hand: relative and absolute densities of four types of mechanoreceptive units in the glabrous skin.J Physiol 286:283-300

34. Edmonds ME, Clarke MB, Newton S, Barrett J, Watkins PJ (1985) Increased uptake of bone radiopharmaceutical in diabetic neuropathy. QJM 57: 843-855

35. Fox RH, Edholm OG (1963) Nervous control of the cutaneous circulation. Br Med Bull 19: 110-114

36. Johnson JM, Brengelman GL, Hales JRS, Vanhoutte PM, Wenger CB (1986) Regulation of the cutaneous circulation. Fed Proc 45: 2841-2850

37. Henriksen O, Paaske WP (1980) Local regulation of blood flow in peripheral tissue. Acta Chir Scand 502: 63-74

38. Kastrup J, Norgaard T, Parving HH, Lassen NA (1987) Decreased distensibilty of resistance vessels of the skin in type 1 (insulin dependent) diabetic patients with microangiopathy. Clin Sci 72: 123-130

39. Palmer RMJ, Ferrige AG, Moncada S (1987) Nitrous oxide release accounts for the biological activity ofE.D.R.F. Nature 327 : 524-526

40. MacIntyre DE, Pearson JD, Gordon JL (1978) Localisation and stimulation of prostacyclin production in vascular cells. Nature (Lond) 271:549-551

Received: 17 July 1991

and in revised form: 30 September 1991

Dr. M.J. Stevens,

5570, Medical Science Research Building II,

Box 0678, The University of Michigan,

Ann Arbor, Michigan, 48109

USA 